\title{
Congenital deficiency in alpha-fetoprotein
}

INSERM

\section{Source}

INSERM. (1999). Orphanet: an online rare disease and orphan drug data base. Congenital deficiency in alpha-fetoprotein. ORPHA:168612

Congenital deficiency in alpha-fetoprotein is a benign genetic condition characterized by a dramatically decreased level of alpha-fetoprotein in fetus or neonate. 